\title{
ROBOMAT: UM RECURSO ROBÓTICO PARA O ESTUDO DE ÁREAS E PERÍMETROS
}

\author{
Maria Claudete Schorr Wildner, UNIVATES, mclaudetesw@univates.br \\ Marli teresinha Quartieri, UNIVATES, mtquartieri@univates.br Marcia \\ Jussara Hepp Rehfeldt, UNIVATES, mrehfeld@univates.br
}

\begin{abstract}
Resumo. O presente artigo apresenta resultados decorrentes de atividades oriundas de uma investigação intitulada "Robótica Educativa: um recurso para o estudo de geometria plana no $9^{\circ}$ ano do ensino fundamental", tendo como problema de pesquisa como a Robótica pode contribuir na aprendizagem da geometria plana. Estudo este que foi realizado em uma escola privada do município de Lajeado, Rio Grande do Sul, tendo, como participantes, vinte e sete estudantes do $9^{\circ}$ ano do Ensino Fundamental. Trata-se de um estudo de caso e para levantamento dos dados, foram utilizados um préteste e um pós-teste, além de observações feitas em um diário de campo, fotos, filmagens e, por fim, um questionário de satisfação. Os dados apontaram que os alunos, diante da proposta apresentada, mostraram-se predispostos a aprender os conceitos áreas e perímetros, favorecendo a ocorrência da aprendizagem, sendo assim, a robótica pode ser um meio para auxiliar na aprendizagem de áreas e perímetros.
\end{abstract}

Palavras-chave: Robótica Educativa; Educação Básica; Geometria Plana.

\section{ROBOMAT: A ROBOTICS RESOURCE FOR STUDY OF AREA AND PERIMETER}

Abstract. The present paper presents results about activities raised from a investigation entitled "Educational Robotics: a resource for plane geometry study on the $9^{\text {th }}$ grade of elementary school", as a research problem how the robotics can aids in the plane geometry learning. The study was performed in a private school of Lajeado city, Rio Grande do Sul, where twenty-seven students of $9^{\text {th }}$ grade of elementary school attended. It is a case study and for the data collection, were used a pretest and posttest, besides observations of the field diary, photos, filming and satisfaction questionnaire. The data showed that students, front of the proposal, were predisposed to learn the concepts of area and perimeter, favouring the learning, therefore, the robotics can be a mean for help the learning of areas and perimeters.

Keywords: Educational Robotics; Basic Education; Plane Geometry.

\section{INTRODUÇÃO}

O uso de tecnologias, em especial do computador, vem provocando sensíveis melhorias no processo de ensino e de aprendizagem em escolas e projetos de pesquisas, envolvendo a educação em geral, apresentando resultados importantes em relação à identificação dos esquemas mentais dos alunos e forma de resolução de problemas. (VALENTE et al apud SENGUE et al, 2005). Dessa maneira, seu emprego no ensino, principalmente no de Matemática, oportuniza aos alunos novas descobertas e conceitos, por meio dos quais eles podem utilizar sua criatividade, desenvolvendo, assim, um aprendizado significativo dos conteúdos matemáticos. 
O professor, ao utilizar tais ferramentas, possibilita uma comunicação diferenciada com seus educandos, além de se integrar ao mundo tecnológico, ou seja, embora imigrante, passará a fazer parte do universo dos nativos digitais. Na educação, lidar com estes tem se tornado um desafio e, consequentemente, muitas escolas têm dado atenção a esta nova geração. Seminários, palestras, reuniões sobre esse tema têm sido realizados em instituições, numa demonstração da inquietação dos educadores em relação ao assunto.

Logo, é importante uma maior aproximação e envolvimento com os alunos e, para facilitar esse processo, a utilização das tecnologias é fundamental. Neste contexto, a Robótica pode ser uma delas, já que a geração atual de alunos vem demonstrando interesse pelo tema, sendo perceptível a quantidade de jovens criando protótipos por meio da robótica.

Consequentemente, as escolas estão adotando kits de Robótica como recurso pedagógico. É importante destacar que o baixo custo destes oferecido pelo mercado tem possibilitado sua aquisição também pelas escolas públicas. Para Marins (2013, texto digital), "em vez de quadro-negro e carteiras, a sala de aula tem furadeira, martelos, parafusos, grampos e serra tico-tico", visando à construção dos robôs. Para colocá-los em funcionamento, além dos materiais alternativos, podem ser usados softwares livres.

Assim, considera-se a robótica uma tecnologia presente na atualidade que desperta o interesse e a curiosidade dos alunos e professores. Além de representar um atrativo, sua utilização propicia um trabalho inovador, dinâmico e criativo, embora seja ainda um desafio para muitas escolas. Este deve-se à resistência de parte dos docentes em adotá-la, por não acreditarem, muitas vezes, no potencial desse recurso.

Partindo deste contexto, realizou-se uma intervenção pedagógica com uma turma de $9^{\circ}$ ano do Ensino Fundamental de uma escola privada do município de Lajeado, Rio Grande do Sul, tendo como objetivo geral identificar em que aspectos a Robótica pode contribuir na aprendizagem da geometria plana. A intervenção foi dividida em quatorze aulas, participando desta, vinte e sete alunos. Neste artigo apresentam-se resultados decorrentes de atividades relacionadas ao estudo de áreas e perímetros. Tal ação teve como objetivo reconhecer o que é perímetro e área, onde e como se aplica.

\section{EMBASAMENTO TEÓRICO}

Estudantes nascidos dos anos 80 em diante, não mais se satisfazem em serem apenas ouvintes; desejam assumir papel de destaque. Esse novo contexto tecnológico exige que os educadores repensem o modo de ensinar. "No processo de ensino e aprendizagem, não podemos ser cobradores de conteúdo; mas sim, "construtores" de inteligências" (HAETINGER, 2003, p. 32).

Diante desta nova geração de estudantes, ditos nativos digitais (Prensky, 2001), um dos grandes desafios é aproximar o estudante do conhecimento científico e auxiliando-o na construção desse conhecimento, sendo assim, meios que auxiliam na motivação dos estudantes desta geração precisam ser buscados.

Logo, a robótica pode ser uma aliada na motivação, no desenvolvimento do raciocínio lógico e na resolução de problemas. Com o seu uso, os trabalhos interdisciplinares acontecem de forma prática e criativa, envolvendo conteúdos das diversas áreas do conhecimento. Nas Ciências Exatas, segundo Marins (2013, texto digital), ela se torna importante, já que o aluno precisa utilizar fórmulas matemáticas, conceitos de física, mecânica, raciocínio lógico e noções de planejamento e para conseguir desenvolver seus robôs. 
Castilho (2002, texto digital) enfatiza que os conhecimentos das diferentes áreas se tornam adequados para a troca de ideias entre os envolvidos na construção dos projetos, fato que também é observado durante as aulas de Robótica, onde a busca por soluções faz com que o trabalho em equipe se fortaleça e enriqueça ainda mais os projetos. Neste contexto, é importante unir forças, agir em unidade, trocar informações, ideias, cooperar e colaborar um com o outro para a obtenção de melhores resultados. Na Robótica, o trabalho em equipe é fundamental, pois estimula a troca de ideias e informações durante as aulas.

Além de propiciar ao educando o conhecimento da tecnologia atual, Zilli apud Zilli (2004, p. 40) apresenta as seguintes competências que essa ferramenta pode desenvolver: raciocínio lógico, habilidades manuais e estéticas, relações interpessoais e intrapessoais, utilização de conceitos aprendidos em diversas áreas do conhecimento para o desenvolvimento de projetos, investigação e compreensão, representação e comunicação, trabalho com pesquisa, resolução de problemas por meio de erros e acertos, aplicação das teorias formuladas a atividades concretas, utilização da criatividade em diferentes situações e a capacidade crítica.

Para utilizar a Robótica, é preciso alguma linguagem de programação, pois o protótipo Robótico só funciona a partir do momento em que for programado, sendo importante ressaltar que Papert já utilizava programação por meio da linguagem Logo em 1987. Onde os estudantes programavam e viam os resultados dos seus códigos na tela do computador por meio de uma tartaruga. Nesta época Papert já defendia a importância de utilizar a programação com crianças. Percebe-se muitas vezes que apenas a programação não se torna atraente, não motiva os alunos a resolver problemas por meio dela, sendo assim, a proposta da robótica, é mais atraente. Os alunos percebem os resultados, vêem na prática. Assim, durante a execução ou animação dos protótipos robóticos estudante reflete sobre o resultado, depurando o que observa, e, caso não corresponda com o que planejava, volta a descrever suas ideias.

Utilizar a Robótica necessita pensar no software e no hardware que será utilizado para o seu funcionamento. Como os hardwares, existem no mercado diversos tipos de materiais que poderiam ser empregados na construção de protótipos Robóticos. Porém, a maioria deles tem sido bastante cara, dificultando a sua aquisição pelas escolas. Por isso, sugeriu-se o Arduíno para a utilização da Robótica em práticas pedagógicas. Na construção dos protótipos, foi utilizado material de baixo custo, como 'sucatas', também chamados de materiais alternativos e a placa Arduíno UNO, D’ABREU et al.(2012), afirma que a Robótica Pedagógica de Baixo Custo (RPBC), facilita a inserção nas escolas, tornando-se um recurso atraente e plausível. Para a programação do protótipo robótico chamado de ROBOMAT, utilizou-se o $S 4 A$ (Scratch for Arduíno), linguagem de programação Scratch para Arduíno.

\section{METODOLOGIA DO TRABALHO}

O presente artigo apresenta dados de uma pesquisa que derivou de um estudo de caso de natureza quantitativa e qualitativa. Yin (2010, p. 24) menciona que o "estudo de caso como método de pesquisa é usado em muitas situações, para contribuir ao nosso conhecimento dos fenômenos individuais, grupais, organizacionais, sociais, políticos e relacionados". Partindo do método citado, pesquisou-se como a Robótica poderia contribuir na aprendizagem da Matemática, em particular, no ensino de conteúdos de geometria plana, com estudantes do $9^{\circ}$ ano do Ensino Fundamental.

A prática pedagógica foi realizada em uma instituição privada, situada na cidade de Lajeado, RS. Participaram desta, vinte e sete alunos, e as atividades tiveram a 
duração de quatro semanas. Inicialmente eram realizados dois encontros semanais, sendo estes de cinquenta minutos; houve a junção de três a quatro períodos por dia, também com o tempo de cinquenta minutos na última quinzena, facilitando a realização das atividades, haja vista a programação de robôs exigiu mais tempo.

Para coleta de dados foram utilizados os seguintes instrumentos: pré-teste e pósteste; registros de vídeos e imagens; anotações em um diário de campo, questionário de satisfação. O objetivo do pré-teste era identificar o conhecimento prévio acerca de alguns conceitos relacionados à geometria plana, Scratch e $S 4 A$. As aulas foram realizadas no laboratório de informática, utilizando o software $S 4 A$ e o RoboMat. Os alunos foram desafiados e resolver atividades envolvendo áreas e perímetros por meio do Robomat. Visando verificar os resultados decorrentes da prática pedagógica realizou-se o pós-teste e um questionário de satisfação.

Neste artigo apenas serão apresentadas e discutidas as atividades que envolviam áreas e perímetros, onde os estudantes foram desafiados em programar o RoboMat para calcular e diferenciar áreas de perímetros. Começou-se realizando atividades em conjunto, para depois os alunos trabalharem em seus grupos. Cada grupo tinha seu material, robô, quadro branco, canetão e computador.

\section{ATIVIDADES DESENVOLVIDAS E DISCUSSÃO DOS RESULTADOS}

Com o auxílio do RoboMat e do software $S 4 A$, os alunos desenharem um triângulo no quadro branco com malha. Em seguida, mostraram os ângulos utilizados, a área e o perímetro dos triângulos. Como cada grupo desenhou um triângulo com dimensões diferentes, o mesmo ocorreu com valores dos ângulos, áreas e perímetros. Após o desenho e os cálculos, cada equipe, com o auxílio do Datashow, mostrou a sua solução. Na Figura 1, é possível observar a solução do grupo 4. Para encontrar os valores, seus componentes afirmaram ter somado os quadrinhos, sendo que cada um teria $4 \mathrm{~cm}^{2}$.

Figura 1 - Desenho do Triângulo com auxílio do RoboMat

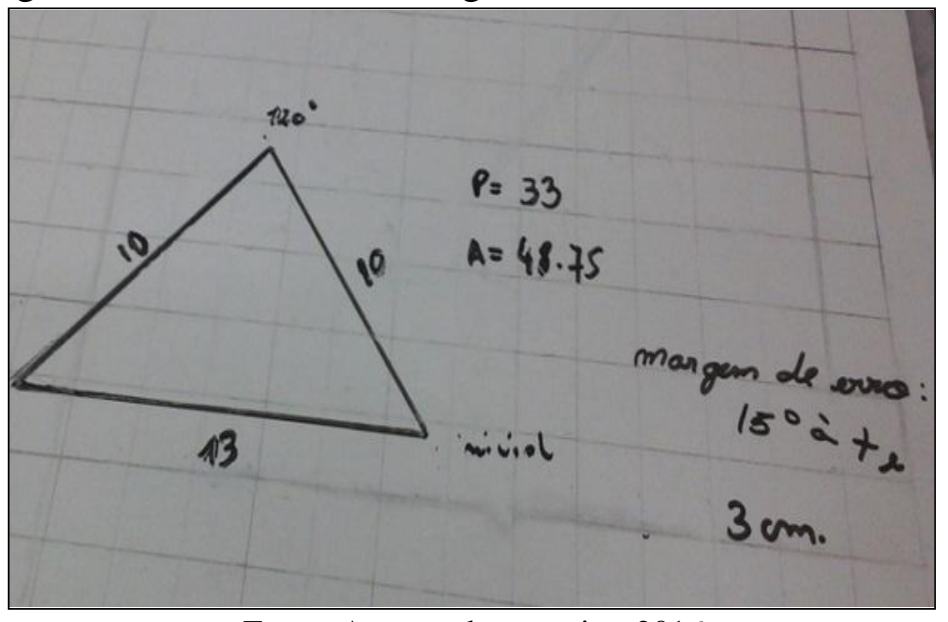

Fonte: Autores da pesquisa, 2016

A aluna A, que era integrante de outro grupo, declarou: "Nós não fizemos cálculo da área assim. A gente usou a fórmula $A=\frac{\text { base } x \text { altura,". Imediatamente, }}{2}$ outros discentes se manifestaram, afirmando que haviam encontrado a área por meio da fórmula. A turma realizou vários testes com a utilização do $S 4 A$ para desenhar o 
triângulo nas medidas que o grupo escolheu. Na Figura 2, é possível ver a programação do grupo 3 fazendo os testes.

Figura 2 - Programação no $S 4 A$ referente ao triângulo, conforme atividade aula 6 , apêndice I

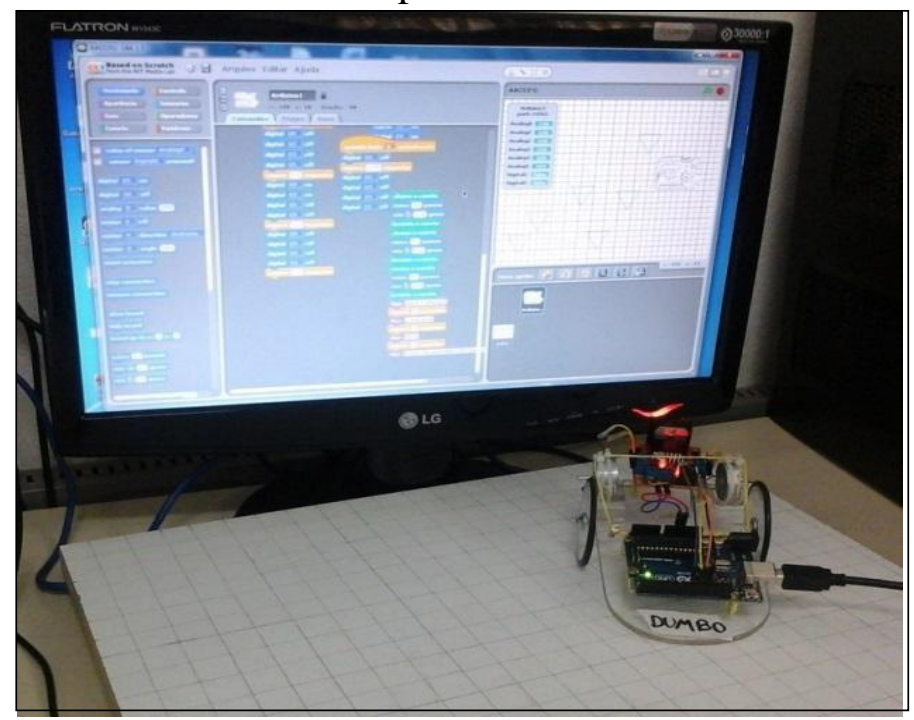

Fonte: Autores da pesquisa, 2016

Os alunos apresentaram também os ângulos utilizados e alguns disseram que estava sendo aprazível trabalhar dessa maneira e com esse material, pois exigia muitos cálculos, principalmente na parte de ângulos. A aluna $\mathrm{F}$ assim se pronunciou:

Nossa, nunca calculei tanto, pois agora preciso pensar no ângulo interno e externo, isto porque o carrinho precisa girar para daí começar a desenhar. Este giro é um ângulo que a gente nunca pensava. Assim é aprender matemática!!. Matemática na prática é bem melhor.

Essa observação nos remete a Papert (1986) onde menciona que não seria necessário a utilização do computador para desenhar um triângulo por exemplo, o mesmo poderia ser feito com papel e lápis, porém enquanto a criança elabora programas, cria hierarquias de conhecimento, onde importantes habilidades são desenvolvidas.

Nessa aula, os alunos utilizaram o transferidor, pois, a cada teste que realizavam, mediam e conferiam o ângulo. Sentiu-se os alunos ansiosos por encontrar os resultados; inclusive, parecia haver uma competição entre os grupos. Assim, foram realizadas atividades com diversas figuras geométricas planas diferentes, até chegar no maior desafios que era calcular a área e perímetro de figuras irregulares.

Para iniciar a atividade com figuras irregulares, foi projetada uma figura em formato de bandeirinha com o auxílio do Datashow, questionando os alunos sobre que figura estaria sendo projetada. Ao serem questionados sobre o que estavam visualizando, alguns responderam que se tratava de uma bandeirinha. $\mathrm{O}$ aluno $\mathrm{L}$ afirmou que via um retângulo e dois triângulos. Segundo o aluno A, se olhássemos por esse lado, poderíamos também afirmar que seriam dois trapézios. À medida que seguíamos com o diálogo, diferentes respostas surgiam.

Em seguida, solicitou-se que desenhassem a figura com o auxílio do RoboMat (Figura 3) no quadro branco sob a malha. A programação exigiu deles um tempo significativo, haja vista a necessidade de calcularem os ângulos para depois programarem o RoboMat utilizando o $S 4 A$. 
Figura 3 - Desenho da Bandeirinha

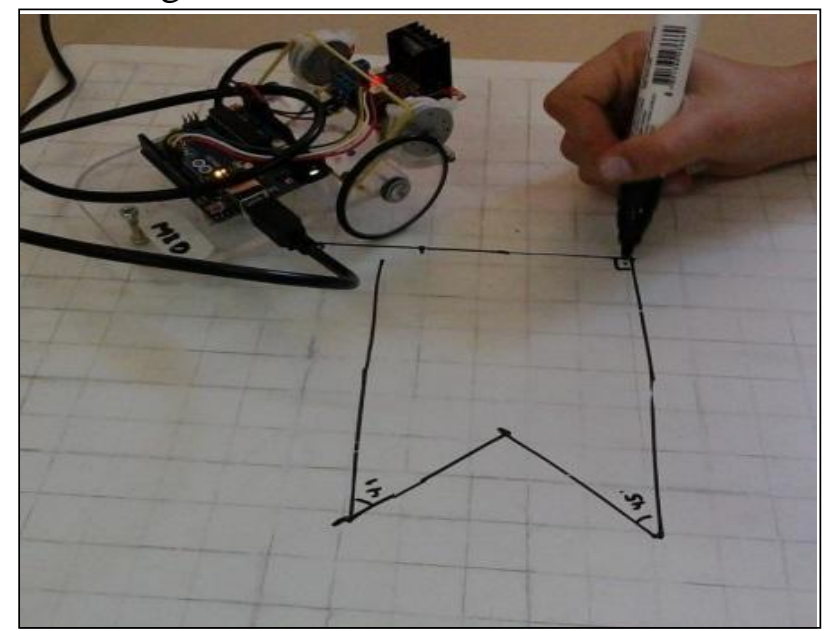

Fonte: Autores da pesquisa, 2016

Os integrantes do grupo 1 logo conseguiram desenhar a bandeirinha e iniciar o trabalho para encontrar o valor da área e do perímetro. Para isto, dividiram a figura em três partes, sendo dois triângulos e um retângulo. Calcularam a área de cada figura separadamente e, em seguida, somaram-nas. Para calcular o perímetro, utilizaram uma régua e mediram o contorno da figura.

O grupo 3 precisou de um tempo maior devido à demora em encontrar os ângulos e programar o RoboMat. O grupo 2 utilizou o $S 4 A$ e, para desenhar a bandeirinha, programou-a primeiro no Scratch; a partir disso, contou os quadrinhos da malha do Scratch e, ao somá-los, encontrou o valor da área e do perímetro. Já o grupo 4 faltou e realizou a atividade no dia seguinte. Seus integrantes também encontraram os valores fazendo a soma dos quadrinhos.

Acompanhar e observar o processo utilizado pelo aluno para chegar à resposta é função do docente, o que me levou a perceber a importância dessa atividade. Para Ausubel (2003), a interação dos estudantes com a nova ideia de instrução e sua relevância na estrutura cognitiva constituem um novo processo de aprendizagem significativa, dando a esta um novo sentido. Inicialmente, para alguns discentes, não estava clara a diferença entre o cálculo da área e do perímetro. Mas, concluída a atividade, conseguiam se posicionar quanto ao cálculo dos dois valores, utilizando, inclusive, formas diferentes de encontrar os resultados. Paulatinamente, com erros e acertos, foram ajustando a programação até a solução. Segundo Papert (1986, p. 50),

O educador deve atuar como um antropólogo. E, como tal, sua tarefa é trabalhar para entender que materiais dentre os disponíveis são relevantes para o desenvolvimento intelectual. Assim, ele deve identificar que tendências estão ocorrendo no meio em que vivemos. Uma intervenção significativa só acontece quando se trabalha de acordo com essas tendências $[\ldots]$.

Diferentemente de Papert (1986), que utilizava o LOGO como linguagem de programação para explorar a matemática com as crianças, nesta pesquisa, os alunos, utilizaram a linguagem de programação Scratch, bem como a robótica. Nesta perspectiva, foram ampliando seus subsunçores e construindo novos conceitos matemáticos.

Como atividade final os alunos receberam uma figura irregular e por meio do Robomat desenharam a mesma no quadro com a malha (Figura 4), depois encontraram a área e perímetro, apresentando os resultados para os colegas.

Figura 4 - Desenho do grupo 1 referente à atividade final 


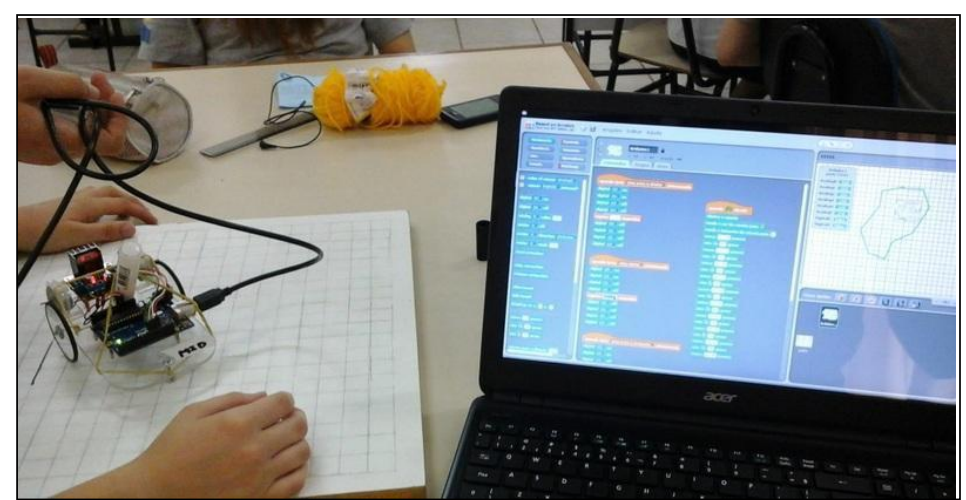

Fonte: Autores da pesquisa, 2016

Para encontrar a medida do perímetro, o grupo 1 utilizou barbante, contornando a figura e depois com o auxílio de uma régua mediram o barbante. No conjunto da atividade, os alunos fizeram uma programação única, onde o programa desenhava a figura e, na sequência, expunha o valor do perímetro e da área. Na Figura 5, aparece a parte da programação em que, por meio do RoboMat, foi desenhada a figura no quadro branco.

Na Figura 6, apresento o código fonte que os alunos do grupo 1 utilizaram para desenhar a figura na tela do computador, contendo como fundo uma malha, e os cálculos e resultados do perímetro e da área. Em síntese, colocaram os códigos apresentados nas Figuras 5 e 6 em um único arquivo, executando os dois em sequência.

Figura 5 - Código fonte usado para desenhar a figura por meio do RoboMat

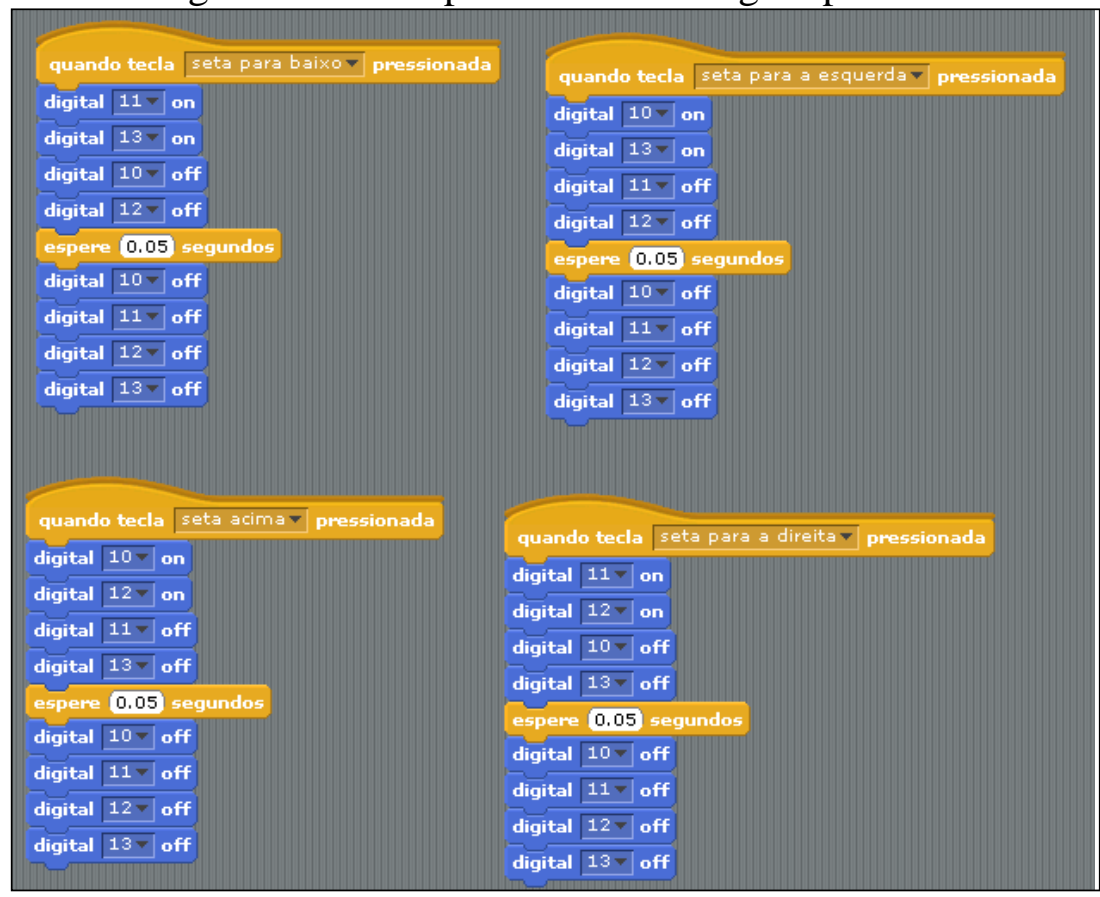

Fonte: Autores da pesquisa, 2016

Figura 6- Código fonte para desenhar a figura na tela do computador, calcular e apresentar os resultados 
8

\begin{tabular}{|c|c|c|c|}
\hline Quanda teda & $\begin{array}{l}\text { Cepen } 0.5 \\
\text { mova } 15 \text { passos }\end{array}$ & copen 0.5 copundas & cospen 0.5 cegandos \\
\hline abaike a caneta & espene 0.5 segundas & Copsen 0.5 segundos & $\begin{array}{l}\text { mova } 15 \text { passos } \\
\text { cepent } 0.5 \text { regundor }\end{array}$ \\
\hline mude o tamanho da caneta para 5 & mova 15 passos & mova 15 passos & mova 15 passos \\
\hline mova 15 passos: & Evere 0.5 segundos & 0.5 segundos & cerpen 0.5 regandes \\
\hline 0.5 sogundos & mova 15 passos & mova 15 passos & vire $\$(50$ graus \\
\hline mova 15 passos: & ceppere 0.5 cegundas & 0.5 copundos & mova 15 pasasos \\
\hline 0.5 cegundos & vire \& 90 graus & mova 15 passos & Epere 0.3 sepundos \\
\hline mova (15) passos: & mova 15 passos & 0.5 segundos & mova 15 passos \\
\hline copers 0.5 cepundios & Cepare 0.5 negunbas & mova 15 passos & epere 0.5 segundos \\
\hline mova 15 passos & mova 15 passos & 0.5 sepundos & mova 15 passos \\
\hline 0.5 cepundas & Capan 0.5 regundos & mova 15 passos & espers 0.5 segundos \\
\hline mova 15 passos: & mova 15 passos: & Even 0.5 segundos & vine if 50 graus \\
\hline cespere 0.5 senundas & Cepere 0.5 segundas & vire $\$ 30$ grous & mova 15 passos \\
\hline mova 15 passos & vire $\&$ \& 40 graus & mova 15 passos & 0.5 sogsindos \\
\hline espere 0.5 segundos & mova 15 passos & Epen= 0.5 segundes & mova 15 passos \\
\hline mova 15 passos & Espene 0.5 segundas & mova 15 passos & 0.5 sogundas \\
\hline ceppen 0.5 cegundos & mova 15 passos & 0.5 regundos & vire $\mathbb{3 0} 30$ graus \\
\hline vire $\&$ (40) graus & Eapene 0.5 segundas & mova 15 passos & levante a caneta \\
\hline mova 15 passos: & mova 15 passos & copen 0.5 segundors & diga 0 Perímetro é.... par 2 segundos \\
\hline Cupene 0.5 segundes & espere 0.5 segundos & vire $\&$ 50 graus & \\
\hline mova 15 passos & mova 15 passos & mova 15 passos & diga $14+6+8+9+16+8+8+9.5+9.5+14$ \\
\hline copere 0.5 segundos & epere 0.5 segundas & Espere 0.5 segundos & \\
\hline mova 15 passos: & vire $\&+70$ graus & mova 15 passos & dìna Aa área é.... por 2 sequndos. \\
\hline copere 0.5 segundas & mova 13 passos & Epene 0.5 segundos & diga $(105+9 \cdot 4)$ por $(2$ segundos \\
\hline vire 540 graus & Seran 0.5 negundas & mava 15 passos & \\
\hline mova 15 passos & mova 15 passos & Evene 0.5 seguntos & \\
\hline
\end{tabular}

Fonte: Autores da pesquisa, 2016

Após a realização da atividade, cada grupo expôs aos demais colegas como encontrou os resultados e a lógica que utilizou para chegar às respostas. Seus componentes mostraram o código fonte da programação desenvolvida e também o desenho feito por meio do RoboMat no quadro branco. Essa atividade foi relevante, pois todos puderam observar que não havia nenhuma programação exatamente igual, ou seja, visando aos resultados, cada equipe usou uma sequência lógica diferente.

Um componente de um dos grupos, durante a apresentação, declarou: "tivemos que refazer várias vezes o programa até acertar, mas acertamos, achamos a maneira correta. Erramos algumas vezes, mas chegamos lá".

Numa aula de matemática típica, a reação da criança a uma resposta errada é tentar esquecê-la o mais rápido possível. Mas no ambiente LOGO ela não é criticada por ter feito um erro ao desenhar. O processo de debugging é uma parte integrante do processo de compreensão de um programa. O programador é encorajado a estudar o bug ao invés de esquecê-lo. No contexto da Tartaruga há uma boa razão para estudá-lo: vale a pena (PAPERT, 1986, p. 85).

A citação acima permite afirmar que os estudantes, ao programarem o computador, encorajam-se para encontrar a maneira correta, pois, caso errarem, não sofrem críticas e, assim, acabam entrando em um processo de debugging. Enquanto Papert (1986) utilizava o LOGO como linguagem de programação para trabalhar a geometria, nesta pesquisa, os estudantes usaram o $S 4 A$.

\section{CONSIDERAÇÕES FINAIS}

Após a análise das atividades dos grupos, percebeu-se que todos conseguiram calcular a área e o perímetro da figura proposta. No pré-teste, antes da intervenção, nenhum dos alunos conseguia calcular a área e o perímetro de figuras irregulares. Diante disso, conclui-se que as atividades realizadas com o uso da robótica e da lógica 
de programação contribuíram para a construção do conhecimento da turma, em particular, os conteúdos de geometria plana.

Acredita-se que, por meio da programação, o aluno aprende com os seus erros. Papert (1986) utilizava a linguagem LOGO para trabalhar com as crianças e, naquela época, já defendia que, através da programação, elas estariam desenvolvendo o seu aprendizado como epistemólogos, ou seja, aprendendo a pensar articuladamente.

\section{REFERÊNCIAS BIBLIOGRÁFICAS}

ARDUÍNO. Disponível em: 〈http://www.arduino.cc/>. Acesso em: 16 set. de 2016. AUSUBEL David P. Aquisição e Retenção de Conhecimentos: Uma perspectiva Cognitiva. Paralelo Editora, LDA. LISBOA. $1^{\text {a }}$ Edição. Janeiro de 2003.

CASTILHO, Maria Inês. Robótica na Educação: Com que objetivos?

(Monografia de Especialização em Informática na Educação) - Universidade Federal do Rio Grande do Sul, Porto Alegre, 2002. Disponível em: <http://www.pgie.ufrgs.br/alunos_espie/espie/mariac/public_html/robot_edu.html $>$. Acesso em: 18 out. 2016.

D’ABREU, João Vilhete Viegas et al. Robótica Educativa/Pedagógica na era Digital. II Congresso Internacional TIC e Educação, Lisboa- Portugal, 2012. Disponível em: < http://ticeduca.ie.ul.pt/atas/pdf/158.pdf>. Acesso em: 22 fev 2014.

D’ABREU, João Vilhete Viegas. Ambiente de aprendizagem baseado no uso de dispositivos robóticos automatizados. In: VALENTE, José Armando; MAZZONE, Jaures; BARANAUSKAS, M. Cecília C. (Orgs). Aprendizagem na era das tecnologias digitais. São Paulo: Cortez: FAPESP, 2007.

HAETINGER, Max Günther. Informática na Educação: Um olhar Crítico. Coleção Criar, Vol.02, 2003.

YIN, R. K. Estudo de caso: planejamento e métodos. 4. ed. Porto Alegre: Bookman, 2010.

MARINS, Lucas. Robôs enriquecem o currículo escolar e estimulam o cérebro. Gazeta do Povo, Londrina, 10 set. 2013. Disponível em: <http://www.gazetadopovo.com.br/educacao/conteudo.phtml?id=1407079>. Acesso em: 26 out 2016.

PAPERT, Seymor. Logo: computadores e educação. $2^{\circ}$ ed. São Paulo: Editora Brasiliense, 1986.

PAPERT, Seymor. A máquina das crianças: repensando a Escola na Era da Informática. Porto Alegre: Artes Médicas, 1994.

PRENSKY, Marc. Digital Natives, Digital Immigrants. MCB University Press, 2001.

VALENTE, José Armando et al. (orgs). Aprendizagem na era das tecnologias digitais. São Paulo: Cortez: PAPESP, 2007. 
VALENTE (org). Computadores e Conhecimento: repensando a educação. Campinas, Unicamp. P. 135-174, 1993.

ZILLI, Silvana do Rocio. A robótica educacional no ensino fundamental: Pespectivas e práticas. Dissertação de mestrado, Programa de Pós-graduação em Engenharia de Produção, Universidade Federal de Santa Catarina, 2004. Disponível em:

$<$

https://repositorio.ufsc.br/xmlui/bitstream/handle/123456789/86930/224814.pdf?sequen $\underline{\mathrm{ce}=1}$ >. Acesso em: 31 set. 2016.

ZILLI, Silvana. Robôs em sala de aula aumentam a motivação dos alunos. UOL Educação. Disponível em: < http://educacao.uol.com.br/noticias/2011/05/19/robos-emsala-de-aula-aumentam-motivacao-dos-alunos-diz-educadora.htm>. Acesso em: 22 set. 2016. 